\title{
Design of a Linear Actuator Driven Solar Tracker for High Concentration Photovoltaics Technologies
}

\author{
Christian Dávila-Peralta, Rafael Cabanillas-López, Rafael García-Gutiérrez, and Ricardo \\ Rodríguez-Carvajal
}

\begin{abstract}
A CPV solar tracker design is described using CAE tools. A virtual wind tunnel simulation and finite element analysis software to calculate the stress and deformation is used. A 'tilt-roll' tracker employs an inexpensive linear actuator and dampers system to drive the tilt axis, also a bar mechanism driven with another linear actuator in the 'roll' axis is utilized. The process to calculate the aperture angle losses caused by the wind drag is discussed.
\end{abstract}

Index Terms -Solar tracker, CPV, finite element analysis.

\section{INTRODUCTION}

The CPV technology transforms solar radiation to electric energy. This process requires tracking the apparent moving of the sun along the day. To that purpose, it must integrate an automatic structure capable to track the sun, and place the optics of the concentrator in a way that the direct solar radiation is always focused on the modules during the day [1].

According to Angel [2], HCPV technology should compete successfully against the fossil based electricity generation dropping total installation costs respect to flat PV systems. There are various types of solar tracking mechanisms described in literature. Mousazadeh [3] analyzed the principles and methods of solar tracking to maximize the power output of solar systems, finding that the most popular and efficient tracking architectures are the polar axis and altazimuth systems. Actually most of the commercially available CPV systems use a 2 axis tracking in an altazimuth configuration with a pedestal tracker followed by the 'tilt-roll' or 'polar' configuration.

The first tracking control systems employed analog sensors to detect the sun and align the mechanism toward it, based on shadowing technologies with light sensors, integrating a closed loop control with motor that drove the mechanism. The developing of low cost microcontrollers motived the appearance of solar tracking systems, that no longer require

Manuscript received May 8, 2015; revised July 30, 2015. This work was supported by the Mexican Science Council (CONACYT) with the grant "Fondo Sectorial de Sustentabilidad Energética" for the Mexican Energy Innovation Center (CEMIEsol) in the $\mathrm{P} 03$ project.

Christian Dávila-Peralta and Ricardo Rodríguez-Carvajal are with the Industrial Engineer Department, University of Sonora, Hermosillo, SON $83000 \quad$ Mexico (e-mail: cdavila@vinculacion.uson.mx, ricardo@industrial.uson.mx).

Rafael Cabanillas-López is with the Department of Chemical Engineering and Metallurgy, University of Sonora, Hermosillo, SON 83000 Mexico (e-mail: rcabani@iq.uson.mx).

Rafael García-Gutiérrez is with the Physics Research Department, University of Sonora, Hermosillo, SON 83000 Mexico (e-mail: rgarcia@ cifus.uson.mx). sensors and which are based only on the digital calculation of high precision analytics equations of solar positioning [1].

The function of a concentration solar tracker is align permanently the aiming axis of the concentration system with the local solar vector, in a way that the maximum power output is produced. In flat PV systems the solar tracking will enhance the power gain of a PV array, but in this installation exists some issues like the cost, liability, energy consumption, maintenance and performance, which should be taken into account [3].

For the layout of solar trackers the wind loads are critical and therefor they should be known as precisely as possible [4]. The operation conditions for solar trackers consist in set a maximum wind speed value during the operation of tracking. The higher is this wind speed, the heavier and more expensive the structure will be in order to keep the deformations below a level for an accurate tracking. An economical and efficient approach is to determine the maximum service wind speed (MSWS) by a cross-correlation between the wind speed and the direct solar radiation, in the site in which is planned to install the tracker. When the wind speed is above this value, the stiffness specs are not to be accomplished and the tracker can change to stow mode where the wind drag reduces to its minimum.

Another variable involved in the service conditions characterization is the max deformation accepted, measured in the aperture surface, and which has the intention to establish a limit in the CPV modules acceptance angles loses caused by the flexibility of the solar tracker. Determining the value of maximum allowable deformation depends on the particular CPV acceptance angle, to which the follower is designed, keeping in mind that the final accuracy of this will be comprised within the acceptance angle under total CPV array [1].

The wind loads produces stress and deformation in the tracker components and it must be calculated to ensure, first its structural reliability, and second, the effect of the deformations in the acceptance angle. Peterka and Derickson [5] studied extensively the wind loads in heliostats using wind tunnels. Their reports documented the load coefficients for the mayor components. Subsequent studies [4] repeated the experiment with heliostats with different shapes, changing the aspect ratio, finding correlation between the wind drag and the radius of the collecting surface form or reflecting surface in the case of heliostats.

Currently the use of finite element analysis (FEA) for the calculation of the max deformation has been widely used for studies reported in the literature. Chih-Kuang [6] made a simulation of the wind loads using a commercially available 
computer fluid dynamics (CFD) software. The determined values of the wind induced pressures in the solar tracker where introduced to a structural FEA software to calculate the stress and displacement on the tracker structure. To prove their results, they manufacture a solar tracker in order to make measurements with deformation cells, taking into account the gravity loads only.

Gong et al. [7] conducted a study to determine the wind-induced dynamic response on a heliostat. Using a wind tunnel, pressure coefficients were determined and compared with those of Peterka and Derickson [5]. These values were introduced to a FEA software to calculate the displacement, the stress distribution and the natural frequency of the structure.

\section{Solar Tracker Design Process}

The design process starts with a strategy in order to get a functional and inexpensive design that can be manufactured and assembled locally. The design strategy takes into account the next points:

1) The solar tracker design to be used with the concentration modules made by the University of Arizona [8].

2) It is considered as an ideal design the one that meets the specifications of weight per square meter in the structure raised by Angel et al. [2] of $23 \mathrm{~kg} / \mathrm{m} 2$ collector.

3) The max wind speed on stow position and the MSWS considered is 39 and $11 \mathrm{~m} / \mathrm{s}$ respectively, as recommended by Luque-Heredia [1].

4) Loses in the acceptance angle caused by deformation in the structure are to be less than about a half the acceptance angle of the optic array.

5) A novel design will be pursued, in order to obtain some transferable intellectual property protection (i.e. a patent).

6) Priority on the cost reduction.

As a result of the design strategy, the team rise with a linear actuator driven solar tracker, using a tilt-roll configuration as showed in Fig. 1. This design uses a linear actuator in the 'tilt'axis, with a couple of hydraulic dampers set up in parallel with it. A second actuator drives a bar linkage which turn the concentrators around the 'roll' axis. The tracker was designed to carry 12 concentration modules in a $6 \times 2$ configuration, in which each 2 module array are to 'roll' in the same axis, and parallel to the other 6 arrays.

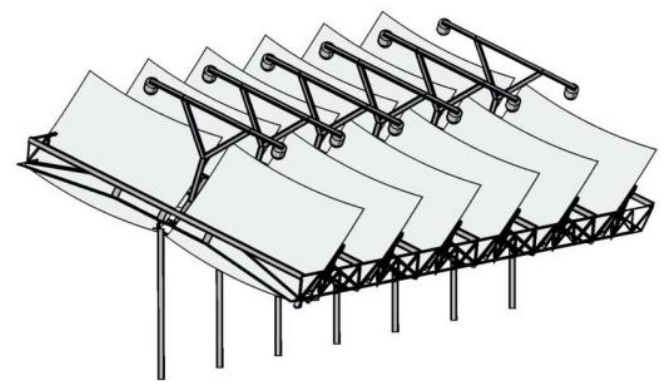

Fig. 1. Linear actuator driven polar solar tracker.

\section{DefinING ThE MAXIMUM APERTURE ANGLE LOSES}

The next step was to determine the maximum allowed deflection, in terms of an aperture angle. As defined by Coughenour et al. [8] the optical array of the technology created in the University of Arizona let the acceptance angle to be as long as $\Theta= \pm .75^{\circ}$. Each module is made by a $1.65 \times$ $1.65 \mathrm{~m}$ square shape parabolic mirror, with $1.5 \mathrm{~m}$ of focus length, where a second optic stage is made by a silica spherical lens, which distributed the solar radiation in a multi-junction PV cells placed behind the sphere in a curved surface, even when the tracking is out of axis. This optical array let an acceptance angle of $1.5^{\circ}$, relaxing the requirements of the solar tracking. The Fig. 2 shows a diagram of the optics operation, showing the projection of the solar image in the curved surface (a), representing the solar rays in an on-axis tracking (b), and in an off-axis tracking.

As discussed above, the aperture angle loses are caused by many reasons like manufacturing tolerance, mounting misalignment, and the deformation in the structure on service conditions. As the contribution of each individual error sources are not know precisely, the team choose a $1 / 2$ of the acceptance angle of the modules to be lose by the structural displacement, caused by the wind drag or the gravity effect.
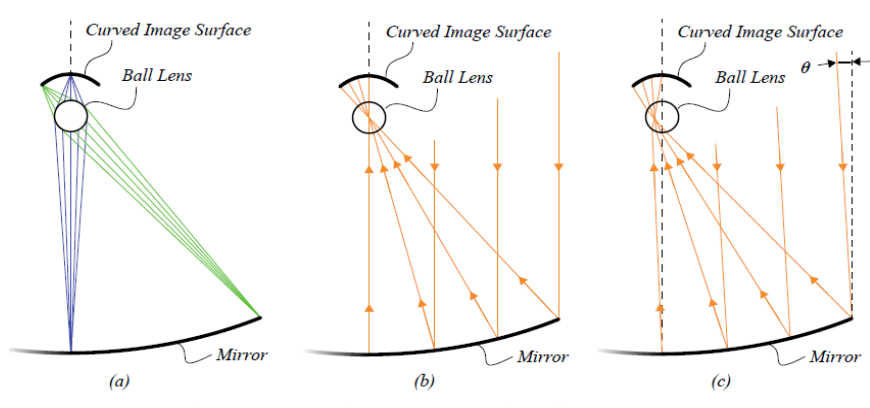

Fig. 2. UA optic array operation diagram [7].

\section{EsTiMATING WIND LOADS}

Previous studies [9] showed that at least $95 \%$ of the direct solar radiation is available at wind speeds not higher than 11 $\mathrm{m} / \mathrm{s}$. "This wind speed value below which this $95 \%$ cumulated direct irradiation is comprised seems, in first instance, a reasonable choice to be taken as the maximum service wind speed, over which the tracking control can order a stow position" [1]. Therefore, the next step was to make a virtual simulation to obtain the wind drag forced caused by that speed in services conditions. As Peterka and Derickson [5] proposed, 4 scenarios where studied with the MSWS: $(\alpha: 90$, $\beta: 0),(\alpha: 30, \beta: 0),(\alpha: 90, \beta: 65),(\alpha: 0, \beta: 0)$ for scenarios $1,2,3$ and 4 respectively. Also, a maximum wind speed of $39 \mathrm{~m} / \mathrm{s}$ where studied with the stow position (scenario 4 ). $\alpha$ and $\beta$ angles are shown as presented by Peterka and Derickson [5] in Fig. 3.

A wind flow analysis was performed with SolidWorks for one array of mirrors, since the mirrors were the only parts that present a mayor wind drag. The effect of the wind drag on the power units were also studied, although its value was no significant. The pressure calculated by the simulation was then converted into punctual forces placed where the mirror will be bolted to the structure in the finite element analysis. Fig. 4, shows the wind drag simulation for scenario 2. Table I shows the normal pressure values encountered for the same scenario. 


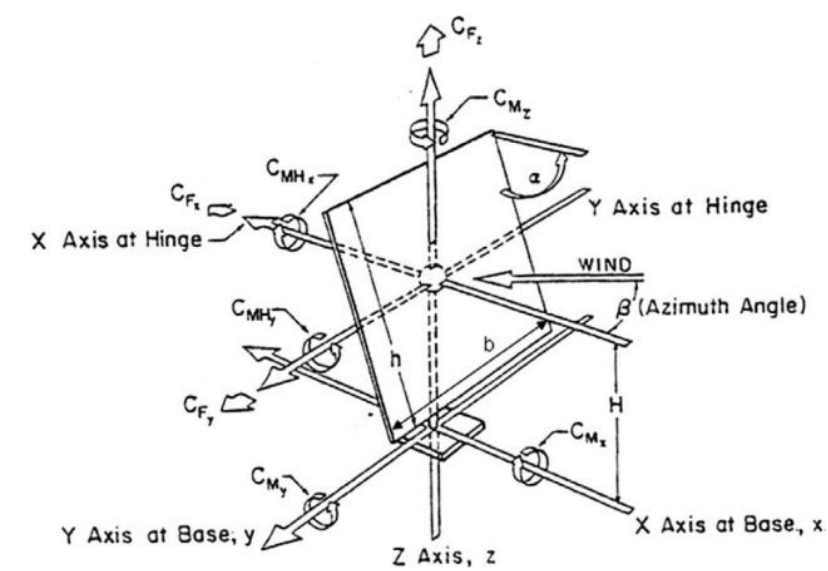

Fig. 3. Peterka and Derickson [5] proposed coordinate system.

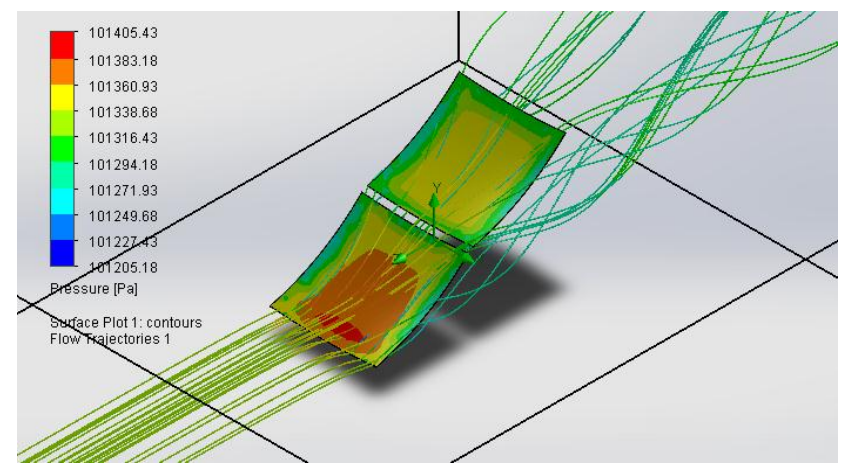

Fig. 4. Wind drag analysis using SolidWorks.

TABLE I LOCAL PARAMETERS

\begin{tabular}{lccll}
\hline \hline Parameter & Minimum & Maximum & Average & $\begin{array}{l}\text { Surface } \\
\text { Area }\left[\mathrm{m}^{2}\right]\end{array}$ \\
\hline $\begin{array}{l}\text { Pressure } \\
{[\mathrm{Pa}]}\end{array}$ & 101224.87 & 101463.94 & 101335.42 & 11.15 \\
\hline \hline
\end{tabular}

\section{FinIte ELEMENT ANALYSIS}

For FEA study, the structure was separated into 3 stages to simplify the analysis. First, the 'roll' structure where the solar optical assembly is mounted was loaded with the wind drag forces. The places where the 'roll' structure is joined with the next stage, called the 'tilt' structure, where fixed with pin joints for convenience. The FEA analysis was performed using the frame analysis module of the Inventor Software. Fig. 5 and Fig. 6 shows the stress and displacement output for scenario 3 , respectively.

The reaction values on the pinned fixed boundary condition where used as forces in the next stage of the structure, and so on to the third stage. In the scenario 4, the boundary conditions that represent the points where the hydraulic dampers are connected to the tilt structure, where set as fixed pinned, because they are supposed to work as a structural member in high speed wind gusts, when the damping force opposes to the direction of the movement. If the dampers are magnetoreological, its viscosity can be controlled in convenience to "lock" the tilt axis in a fixed position during the day.

Fig. 7 shows the stress output for the scenario 4. Some iterations where made in order to get a lightweight but resistant structure. The displacement was the ruling factor in scenarios 1, 2 and 3, as it simulate the service conditions. In scenario 4 , or say in stow position, the displacement factor was no longer the ruling one, but the stress distribution was to be observed.

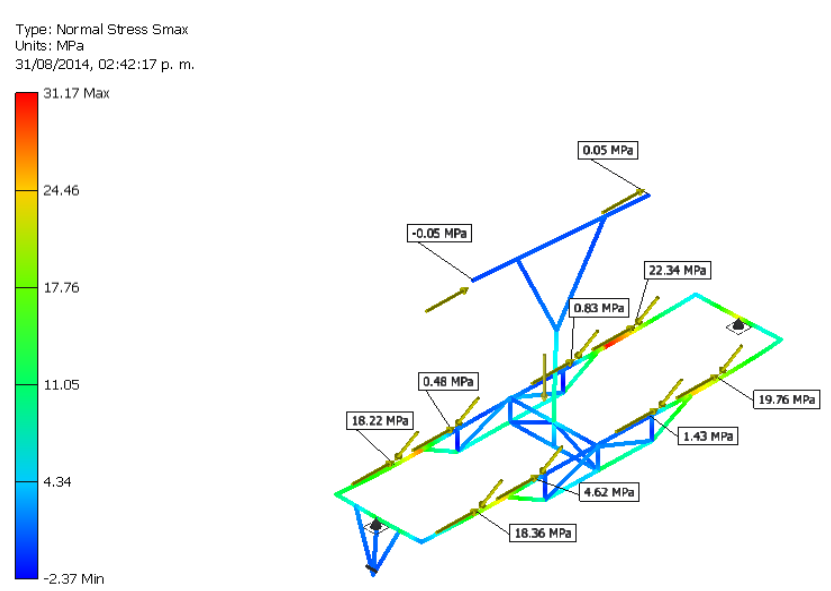

Fig. 5. FEA output: Stress distribution using inventor frame analysis.

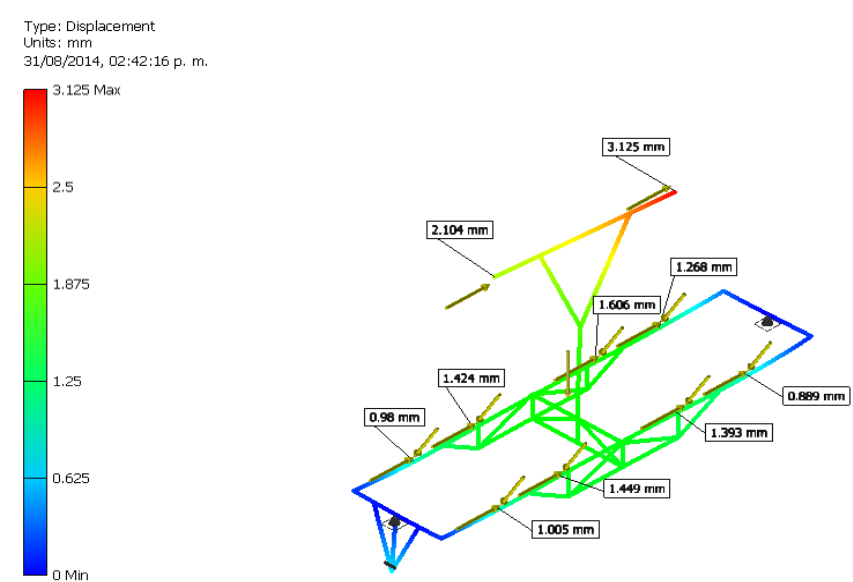

Fig. 6. FEA output: Displacement distribution using inventor frame analysis.

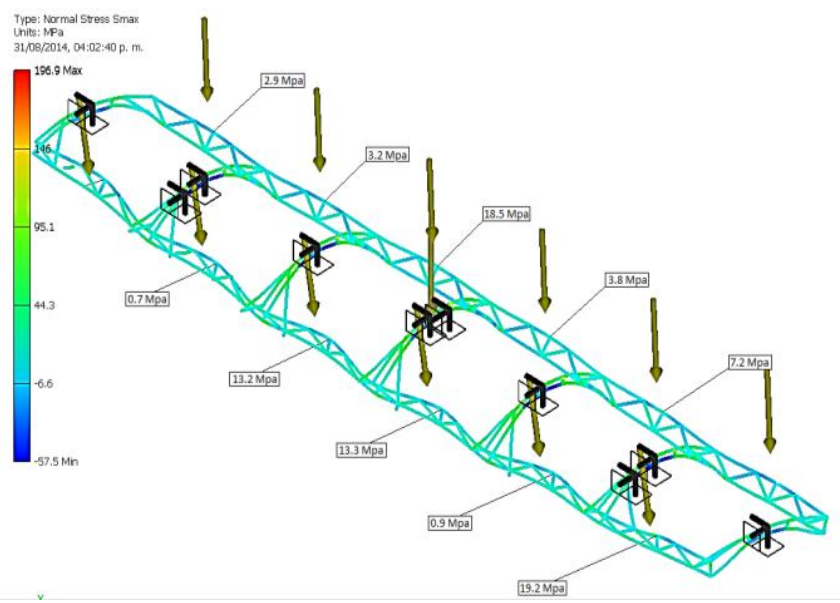

Fig. 7. FEA output: Stress distribution in stow position, scenario 4.

The losses in the aperture angle of the solar tracker, caused by the wind drag and gravity where calculated using the displacement estimated in the FEA analysis in a similar way Luque-Heredia proposed: "...using the bending rotation values of the set of vector normal to the concentrators modules obtained in the FEA simulation, assuming that each CPV module mounted on the aperture could be considered to remain undeformed under service loads, a single normal vector is considered per CPV module..." as seen in Fig. 8.

The sum of all deformations, supposing that these deformations occur in the worst combination possible, caused 
a total displacement of $0.38^{\circ}$. The design team considers this value acceptable, opting for the $0.005^{\circ}$ loss in the aperture angle against the extra weight gained from the next possible structural beam commercially available.

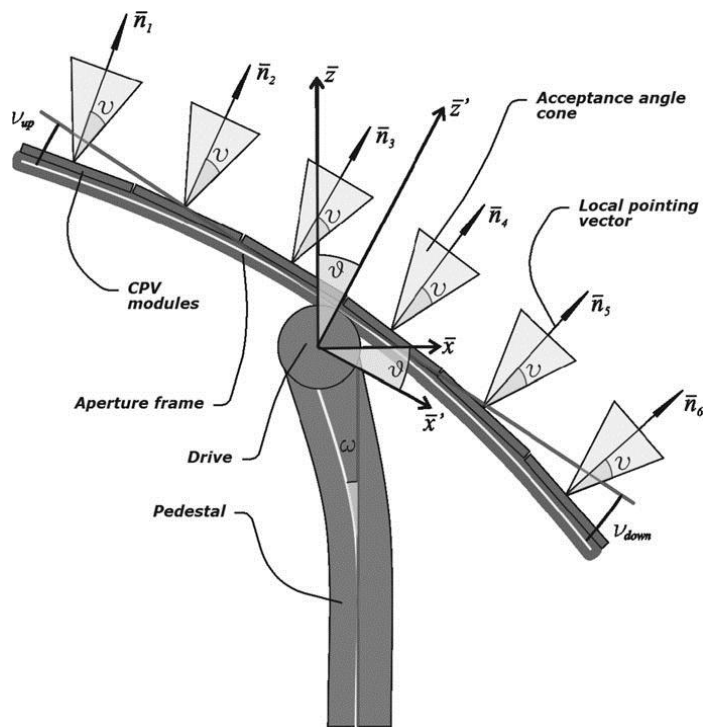

Fig. 8. Cross section of pedestal tracker subject to flexure. At a certain aperture elevation (zenith angle $\theta$ ). The local pointing vector to each module $\eta_{\mathrm{i}}$ and its acceptance angle $(v)$ cone within the apertures local reference system $(x, y, z)[1]$.

\section{CONCLUSION}

The design of the first linear actuator prototype driven by linear actuators was design as a proof of concept to test a lightweight and economical solar tracker architecture for HCPV. The principal benefit of this type of design lie on the use of a couple of linear actuators driving arrays of several concentration units, which are cheaper than slewdrive and other gear based mechanism. To reduce the stress and wind induced deformation, hydraulic dampers are to be placed in parallel to the linear actuator that drives the tilt angle.

Once the prototype has been completed, it will allow measure the deformation in the structure, as well as testing the control systems and the anti-vibration system currently in the development, which will be published in future papers. Currently a patent application has been summited (MX/a/2011/01221).

In order to obtain useful data to build a next generation linear actuator driven solar trackers, the prototype will be tested with different approaches in the National Laboratory of Solar Chemistry and Solar Concentration (LACYQS), located at the Hermosillo Solar Platform (Plataforma Solar de Hermosillo) in the University of Sonora.

\section{REFERENCES}

[1] I. Luque-Heredia, G. Quémeré, R. Cervantes, O. Laurent, E. Chiappori, and J. Ying-Chong, "The sun tracker in concentrator photovoltaics," in Next Generation Photovoltaics, A. B. Cristobal-López, A. Martí-Vega and A. Luque-López, Eds. Springer Series in Optical Science, 2012, ch. 3.

[2] R. Angel, B. Cuerden, and A. Whiteside, "Lightweight dual-axis tracker designs for dish-based HCPV," in Proc. the CPV-10 International Conference on Concentrator Photovoltaic Systems, 2014.
[3] H. Mousazadeh, A. Keyhani, A. Javadi, H. Mobli, K. Abrinia, and A. Sharifi, "A review of principle and sun-tracking methods for maximizing solar systems output," Renewable and Sustainable Energy Reviews, vol. 13. pp. 1800-1818, 2009.

[4] A. Pfahl, M. Buselmeier, and M. Zaschke, "Wind loads on heliostats and photovoltaic trackers of various aspect ratios," Solar Energy, vol. 85, issue 9, pp. 2185-2201, 2011.

[5] J. A. Peterka and R. G. Derickson, "Wind load design methods for ground based heliostats and parabolic dish collectors," Report SAND92-7009, Sandia National Laboratories, Springfield, 1992.

[6] C.-K. Lin, C.-Y. Dai, and J.-C. Wu, "Analysis of structural deformation and deformation-induced solar radiation misalignment in a tracking photovoltaic system," Renewable Energy, vol. 59, 2013.

[7] B. Gong, Z. Li, Z. Wang, and Y. Wang, "Wind-induced dynamic response of Heliostat," Renewable Energy, vol. 38, pp. 206-213, 2012

[8] B. M. Coughenour, T. Stalcup, B. Wheelwright, A. Geary, K. Hammer, and R. Angel, "Dish-based high concentration PV system with Khöler optics," Optical Society of America, vol. 22, 2014.

[9] D. E. Randall and N. R. Grandjean, "Correlation of insolation and wind data for solmet stations," SAND82-0094, Sandia National Laboratories, 1982.

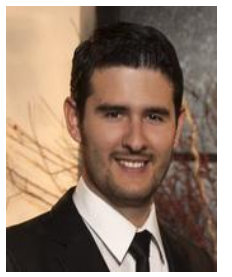

Christian Davila-Peralta lives in Hermosillo, Sonora, México. He was a mechatronics engineer, in ITESM 2009. He also received the Sustainable Development Certificate, from Universidad de Sonora in 2013, and got his master in engineering degree, in systems and technology, Universidad de Sonora in 2015.

$\mathrm{He}$ is actually an academic technician at the University of Sonora, in Hermosillo, México. He has worked on several research and development projects including solar energy and medical industry mechanisms and devices, filling more than 8 patent applications.

Prof. Davila-Peralta is a co-founder of the Solar Energy Research Network in Mexico, and has been working in projects with enterprises and universities to promote the Mexican solar energy industry and supply chain.

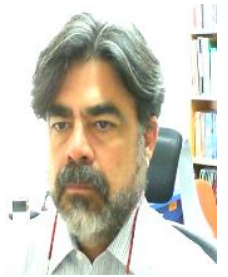

Rafael E. Cabanillas-López lives in Hermosillo, Sonora Mexico. He received the doctoral degree in engineering from Universidad Nacional Autonoma de Mexico in 2001. He is a facultative professor in energy at Chemical Engineering and Metallurgical Department, University of Sonora. His research interests are CFD, interaction convection-radiation in heat transfer problems, and application of concentrated solar energy. Currently, he is a part of the team of Plataforma Solar de Hermosillo (PSH).

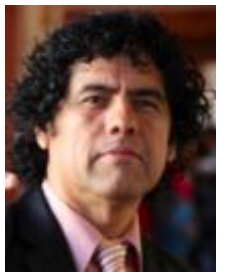

Rafael García-Gutierrez lives in Hermosillo, Sonora, Mexico. He receibed his MSc degree, from CICESE in 1998. He got the PhD degree, from CICESE in 2001. And he was a PosDoc researcher in ASU 2004. He is now a professor-researcher at the University of Sonora.

His research interests are optoelectronics devices, solar cells and solid state lighting, synthesis by CVD, MOCVD, PVD, FCVD, ALD.

García-Gutierrez have more than 25 international papers, 7 patentes and 13 graduated students.

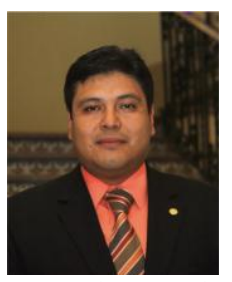

Ricardo A. Rodriguez-Carvajal lives in Hermosillo, Sonora, México. He was an industrial and systems engineer in UNISON in 1999. He got his master degree in computer science, from ITH 2006, and received his doctor degree in strategic planning, from UPAEP, 2013.

He is a member of the National Researchers System CONACYT. He is the co-founder of the Solar Energy 
Wind Energy 
